\title{
DIGITAL PHOTO IMAGE- FORGERY DETECTION TECHNIQUES
}

\section{MURALI S., ANAMI B.S. AND CHITTAPUR G.B.}

Maharaja Institute Of Technology, Mysore, India.

KLE Institute Of Technology, Hubli, India.

Basaveshwar Engineering College, Bagalkot, India.

*Corresponding Author: Email- gbchittapur@gmail.com

\begin{abstract}
Digital images provide a new way to represent pictures and scenes that only film and a darkroom could supply before. This new way to capture and store images opens a door to malicious individuals wishing to forge or otherwise manipulate original authentic images. Since digital photography is improving and becoming more widely used technology, a need exists to provide countermeasures against malicious forgers. The old adage "don't believe everything you hear" is becoming "don't believe everything you see." Photo is considered as evidence in all digital era. Image Forensic area provide right value to authenticated original images. We proposed two algorithm to overcome such challenging problem in the forensic world.

Much time and effort has gone into analyzing uncompressed images but current techniques return dismal success in detecting one of the most common digital image formats, JPEG. In this paper we presented here attempts to tailor methods toward the JPEG format as well as incorporate all image formats where possible.

The proposed method is analogous to a recursive type process, with the sub-processing resembling a "divide and conquer" approach. Block Based Processing is useful because the calculations performed are influenced by only the information present in that particular block. A JPEG image can either be color or grayscale. For grayscale Images we propose direction filter technique and color images JPEG block analysis technique.
\end{abstract}

Keywords- Digital Image, JPEG Block, Color Image, Gray Image, Divide and Conquer, Direction Filter.

Citation: Murali S., Anami B.S. and Chittapur G.B. (2012) Digital Photo Image- Forgery Detection Techniques. International Journal of Machine Intelligence, ISSN: 0975-2927 \& E-ISSN: 0975-9166, Volume 4, Issue 1, pp.-405.

Copyright: Copyright@2012 Murali S., Anami B.S. and Chittapur G.B. This is an open-access article distributed under the terms of the Creative Commons Attribution License, which permits unrestricted use, distribution, and reproduction in any medium, provided the original author and source are credited. 